\title{
Weedy Rice (Oryza sativa L.) Problem in Rice (Oryza sativa L.) Based Cropping Systems in the Philippines
}

\author{
Irene R. Tanzo ${ }^{1}$, Edwin C. Martin ${ }^{1}$, Bhagirath S. Chauhan ${ }^{2}$ \\ ${ }^{1}$ Philippines Rice Research Institute (PhilRice), Maligaya, Muñoz, Nueva Ecija, Philippines; ${ }^{2}$ International Rice Research Institute \\ (IRRI), Los Baños, Philippines. \\ Email: b.chauhan@irri.org
}

Received September $18^{\text {th }}, 2013$; revised October $20^{\text {th }}$, 2013; accepted November $2^{\text {nd }}, 2013$

Copyright (C) 2013 Irene R. Tanzo et al. This is an open access article distributed under the Creative Commons Attribution License, which permits unrestricted use, distribution, and reproduction in any medium, provided the original work is properly cited.

\begin{abstract}
A study was undertaken in February 2012 to understand the knowledge and practices of rice farmers about weedy rice in two municipalities of Iloilo, Philippines. The specific objectives of the study were to establish what rice farmers know about weedy rice, examine rice farmers' practices in managing weedy rice, and recommend policies on weedy rice management based on the results of the study. Farmers' knowledge of weedy rice did not differ much between two villages. Results showed that $41 \%$ from the second most affected village and $33 \%$ from the most affected village thought that weedy rice cannot reduce the market value of the harvested rice. Majority of the farmers (68\%) responded that awns can be absent in some weedy rice and about $40 \%$ of the farmers did not know that seeds of weedy rice have dormancy. Cutting the weedy rice panicles at harvest, as the best way of reducing weedy rice, was practiced by majority of the respondents (82\%) from the most affected village. Our study suggests that there is a need to increase awareness about weedy rice among Asian farmers.
\end{abstract}

Keywords: Knowledge; Awareness; Iloilo; Weedy Rice

\section{Introduction}

Rice is the main staple crop in Asia, including the Philippines. In the Philippines, rice farming is important in the Iloilo province, as rice is one of the major sources of income and food of the province. Based on the most recent national data, Iloilo produced 659,970 Mt of rice in 2010, making it the fourth largest rice producing province in the country [1]. No wonder, the province has been known as one of the rice granaries of the Philippines.

In the past years, however, rice production in the province has been steadily and increasingly affected by an emerging farm problem: weedy rice. Most affected areas are those where direct seeding is commonly practiced. Weedy rice is a serious threat in direct-seeded rice systems as it competes with cultivated rice, decreases crop yield, and reduces market value of the harvested crop due to contamination [2-4]. Site visits in the province showed that rice farmers totally abandoned their paddy fields where severe weedy rice infestation occurred.

Some experimental studies on weedy rice in farmers' fields had been undertaken in Iloilo province. These stu- dies focused on characterization and management of weedy rice. Rice and weed researchers had also established linkages with other organizations to strengthen work on the subject. However, to develop a truly successful strategy to combat weedy rice, there is a need to involve the rice farmers. It is essential to understand how the farmers are affected by weedy rice and what they know about it as these are critical in planning and implementing campaign programs. This is crucial information so that researchers will be able to identify the knowledge gaps and behavioral patterns of farmers towards weedy rice and even learn from their management practices [5]. Such information will facilitate learning and prioritize actions for the development of a successful strategy for weedy rice.

This study was undertaken to understand the knowledge and practices of rice farmers about weedy rice. The specific objectives of the study were to establish what rice farmers know about weedy rice, examine rice farmers' practices in managing weedy rice, and recommend policies on weedy rice management based on the results of the study. 


\section{Materials and Methods}

A knowledge and practice survey was conducted in February 2012 in two municipalities of Iloilo, Philippines namely, Dingle and Barotac Nuevo. Based on ocular inspection and interviews with key informants in the area, weedy rice was most prevalent at these sites in the province and therefore, these sites were chosen. Two villages were purposely selected for each municipality: one village represented the most affected by weedy rice while the other one was the next most affected and adjacent village. For Dingle, the most affected village was Sinibaan and the second most affected village was San Matias. For Barotac Nuevo, the most affected village was Talisay and the second most affected village was Agcuyawan.

For the most affected villages, 30 farmers were randomly selected from each municipality. For the second most affected villages, 15 farmers were randomly selected from each municipality. Thus, a total of 90 rice farmers were interviewed: 60 farmers were from villages most affected by weedy rice and 30 rice farmers from the second most affected villages.

A survey questionnaire was developed, translated in the local dialect, and pre-tested. The instrument focused on the knowledge and practices of rice farmers on weedy rice. Knowledge on weedy rice was captured by asking the farmers if a knowledge statement presented to them was either true, false, or they do not know. The statements focused on three important subject areas of weedy rice namely, its attributes (19 statements), management options (12 statements), and problems caused or effects of weedy rice (6 statements). Rice farmers' practices were captured using close and open-ended questions which established if the knowledge of rice farmers translates to action. In addition, capturing the practices of the rice farmers informed us what needed to be improved, what the study may wish to confirm through experiments, and what we can learn from the farmers. Basic social and farm characteristics of the farmers were also gathered. Local enumerators were trained which facilitated the survey interview and mitigated errors.

Informal interviews with key informants and focus group discussions (FGDs) were also done to acquire additional information which supplemented the survey data. Descriptive statistics such as frequency and ranking were used in the analysis of the data.

\section{Results and Discussion}

\subsection{Socio and Farm Characteristics}

On the average, regardless of area, the farmer respondents were in their mid-fifties (Table 1). The youngest respondent was 25 years old and the oldest was 82 years old. There were a bit more female respondents (53\%) as compared to men (47\%). The respondents had, on the average, 10 years of educational experience; that is, they had at least reached high school.

With regards to farm characteristics, regardless of area, the respondents were generally farm owners (67\%), dependent on rain (48\%) and the national irrigation system (42\%) for their irrigation, and using direct seeding (60\%) of rice (Table 1). The respondents from the most affected village were dependent on farmer/exchange seeds (70\%). On the other hand, more than half $(52 \%)$ of the farmers from the other village used certified seeds, followed by farmer/exchange seeds (38\%).

\subsection{Knowledge of the Attributes of weedy Rice}

There were 19 statements presented to the farmer-respondents which described the attributes of weedy rice. Of these statements, 10 aptly described weedy rice while the remaining nine were incorrect statements about weedy rice characteristics.

Among the 10 true (correct) statements, majority of the farmers from the most affected village considered six statements to be true (Table 2). These statements were: 1 ) weedy rice can be taller than cultivated rice $(100 \%$ farmers); 2 ) it is possible to eat weedy rice (97\%); 3) panicle seeds or grains of weedy rice shatter easily $(87 \%)$; 4) weedy rice seeds left on the soil surface at harvest easily germinate (83\%); 5) weedy rice is more common in direct seeding (82\%); and 6) longevity of weedy rice seeds in soil may last more than one cropping season (80\%). These responses are consistent with the results reported in recent research [6-8].

Two statements were perceived by majority of the farmers from the most affected village to be false: 1) awns can be absent in some weedy rice (68\%), and 2 ) weedy rice is a type of weed in rice (55\%). The statement "seeds of weedy rice have dormancy" had almost equal percentages of respondents who responded true (47\%) and false (40\%). In previous studies, variable dormancy has been reported in weedy rice $[6,8]$. The statement "weedy rice consumes more fertilizer than cultivated rice" had almost a quarter of the respondents (22\%), suggesting that the farmers had little awareness on this aspect.

For the second most affected village, except for one additional statement, the same six statements as that of the most affected village were deemed to be true by majority of the respondents. In addition, the statement "weedy rice is a type of weed in rice" was found true by $60 \%$ of these respondents. The same observation as that of the most affected village can be said for the statements "seeds of weedy rice have dormancy" and "awns can be absent in some weedy rice". The statement "weedy rice consumes more fertilizer than cultivated rice" was perceived by more than half of the respondents (53\%) to be 
Table 1. Socio and farm characteristics of rice farmer-respondents affected by weedy rice (WR) in the Iloilo province of the Philippines ( $\mathbf{N}=\mathbf{9 0})$.

\begin{tabular}{|c|c|c|c|}
\hline Socio-demographic characteristic & Most affected village (60) & Second most affected village (30) & Mean \\
\hline Average age (in year) & 54 & 56 & 55 \\
\hline Youngest Age & 25 & 26 & 25 \\
\hline Oldest Age & 82 & 80 & 82 \\
\hline \multicolumn{4}{|l|}{ Sex (\%) } \\
\hline Female & $57 \%$ & $47 \%$ & $53 \%$ \\
\hline Male & $43 \%$ & $53 \%$ & $47 \%$ \\
\hline Average education attainment (yr) & 10 & 10 & 10 \\
\hline Highest & Graduate & Graduate & Graduate \\
\hline Lowest & Grade 1 & Grade 6 & Grade 1 \\
\hline \multicolumn{4}{|l|}{ Tenure status (\%) } \\
\hline Owner & $66 \%$ & $70 \%$ & $67 \%$ \\
\hline Non-owner & $34 \%$ & $30 \%$ & $33 \%$ \\
\hline \multicolumn{4}{|l|}{ Source of irrigation (\%) } \\
\hline NIS/CIS & $47 \%$ & $34 \%$ & $42 \%$ \\
\hline STW/etc & $5 \%$ & $10 \%$ & $7 \%$ \\
\hline Rain & $47 \%$ & $49 \%$ & $48 \%$ \\
\hline Others & $2 \%$ & $7 \%$ & $3 \%$ \\
\hline \multicolumn{4}{|l|}{ Crop establishment (\%) } \\
\hline Transplanting & $42 \%$ & $36 \%$ & $40 \%$ \\
\hline Direct seeding & $58 \%$ & $64 \%$ & $60 \%$ \\
\hline \multicolumn{4}{|l|}{ Seed class of major variety planted } \\
\hline farmer/exchange & $70 \%$ & $38 \%$ & $58 \%$ \\
\hline Good seeds & $3 \%$ & $9 \%$ & $5 \%$ \\
\hline Registered & $3 \%$ & - & $2 \%$ \\
\hline Certified & $21 \%$ & $52 \%$ & $32 \%$ \\
\hline Hybrid & $3 \%$ & $1 \%$ & $3 \%$ \\
\hline Average size of parcel most affected by WR (in hectares) & 1.02 & 1.07 & 1.04 \\
\hline
\end{tabular}

false. In previous studies in the Philippines and US, weedy rice accessions have been shown with greater nitrogen-use efficiency for shoot biomass than cultivated rice $[9,10]$.

Based on the results of this survey, it is possible that the most affected village may have the worst infestation of weedy rice in the province due to the incorrect knowledge of two major weedy rice characteristics: "awns can be absent in some weedy rice" and "weedy rice is a type of weed in rice". Majority of the farmers from this village opined that weedy rice always have awns, suggesting that they will not be able to control all types of weedy rice in the field. In some weedy rice accessions, awns are absent and in others, they are present [7]. The scenario looks worst if majority of these farmers thought that weedy rice is not a weed as this increases the probability that farmers would not control weedy rice but allow it to grow in their fields. This incorrect knowledge seems to jibe with the belief of the majority that weedy rice can be eaten. FGD results jibed as weedy rice was considered by the farmers as similar to traditional rice and considered by the majority as having "good taste". Additionally, if almost the same farmers from the most affected village believed that seeds of weedy rice have no dormancy, 
Table 2. Farmer-respondents knowledge of the true attributes of weedy rice (WR) in the Iloilo province of the Philippines (N =90).

\begin{tabular}{|c|c|c|c|c|c|c|}
\hline \multirow{2}{*}{ Attributes of weedy rice } & \multicolumn{3}{|c|}{$\%$ MA village $(60)^{1}$} & \multicolumn{3}{|c|}{$\%$ SMA village $(30)^{1}$} \\
\hline & True & False & Not Sure & True & False & Not Sure \\
\hline WR is more common in direct-seeding & 82 & 18 & - & 87 & 13 & - \\
\hline Panicle seeds or grains of WR shatter easily & 87 & 10 & 3 & 97 & 3 & - \\
\hline WR can be taller than cultivated rice & 100 & - & - & 97 & 3 & - \\
\hline WR seeds left on the soil surface at harvest easily germinate. & 83 & 13 & 3 & 90 & 10 & - \\
\hline It is possible to eat WR & 97 & 3 & - & 97 & 7 & - \\
\hline Longevity of WR seeds in soil may last more than one cropping season & 80 & 17 & 3 & 87 & 7 & 7 \\
\hline Seeds of WR have dormancy & 47 & 40 & 13 & 50 & 40 & 10 \\
\hline Awns can be absent in some WR & 33 & 68 & - & 43 & 57 & - \\
\hline WR consumes more fertilizer than cultivated rice & 35 & 43 & 22 & 33 & 53 & 13 \\
\hline
\end{tabular}

${ }^{1}$ MA: most affected; SMA: second most affected.

they will not be very persistent in controlling weedy rice. Such an incorrect knowledge may contribute to the poor management of weedy rice and in effect, increase the infestation of weedy rice in the most affected villages.

In the same light, we may concur that the second most affected village was not the worst infested by weedy rice because majority (60\%) of the farmers knew that "weedy rice is a weed in rice" and that half of them knew that "its seed has dormancy". Therefore, these farmers may be more persistent in controlling weedy rice than those from the most affected village. However, it is also possible that their rice fields are the still infested with weedy rice because they may not be controlling all weedy rice in the field as more than half of these farmers did not know that some weedy rice have awns.

It is worthy to note that the most common characteristic of weedy rice, that is, it shatters easily, was unanimously known to both sets of farmers. However, there were still a small number of farmers (3\%) from the most affected village who did not know this basic weedy rice characteristic. During the FGD, farmers explained that this shattering ability of weedy rice made the weed very hard to control as they have no technique to counter it.

As majority of farmers from both areas thought that the statement "weedy rice consumes more fertilizer than cultivated rice" as false, this was discussed in the FGD. Discussions revealed that the farmers thought that weedy rice consumed less fertilizer as it had lesser tillers, more unfilled grains, or lodged easily. In contrast, the farmers who agreed that weedy rice consumed more fertilizer shared during the FGD that this was so as weedy rice grows taller and faster than cultivated rice. Interestingly, they also reported that growth spurt is observed whenever they apply fertilizer.

Two FGD insights worth noting about weedy rice awns were 1) they make threshing longer by clogging the machine, and 2) they acquire large space which makes rice sacks look fuller but lighter in weight. These valid observations have not been reported in any research.

The results for the incorrect knowledge statements on the attributes of weedy rice were not as straightforward as that of the true/correct statements. Though seven statements (out of nine statements) were correctly thought of as false by majority of the respondents from both villages, the percentages were not as high (Table 3). There was even one statement that was considered as "not sure" by about one third of the respondents from both villages.

For the most affected village, six statements were correctly thought of as false by majority of the respondents. These statement were: 1) weedy rice is late-maturing $(87 \%) ; 2)$ there is only one type/kind of weedy rice (70\%); 3) weedy rice can be harvested with cultivated rice (63\%); 4) weedy rice is only found in Iloilo (62\%); 5) weedy rice have only closed panicles (60\%), and (6) weedy rice has only one kind of panicle (58\%). Two incorrect statements were reported true by majority of the respondents: "flag leaves of weedy rice are always drooping” (90\%) and "grains of weedy rice are all color red” (68\%). The statement "the grain (pericarp) color of weedy rice after milling is always red” almost equally divided the respondents to the categories of true (48\%) and false (50\%).

Surprisingly, the same trend and very similar percentages were found for the second most affected village. 
Table 3. Farmer-respondents knowledge of the incorrect attributes of weedy rice (WR) in the Iloilo province of the Philippines $(\mathbf{N}=90)$.

\begin{tabular}{|c|c|c|c|c|c|c|}
\hline \multirow{2}{*}{ Attributes of weedy rice } & \multicolumn{3}{|c|}{$\%$ MA village ${ }^{1}(60)$} & \multicolumn{3}{|c|}{ \% SMA village ${ }^{1}(30)$} \\
\hline & True & False & Not Sure & True & False & Not Sure \\
\hline WR is late-maturing & 12 & 87 & 2 & 17 & 83 & - \\
\hline WR is only found in Iloilo & 7 & 62 & 30 & 10 & 60 & 30 \\
\hline WR have only closed panicles & 33 & 60 & 7 & 30 & 70 & - \\
\hline WR can be harvested with cultivated rice & 37 & 63 & - & 33 & 67 & - \\
\hline There is only one type/kind of WR & 28 & 70 & 2 & 17 & 77 & 3 \\
\hline The grain (pericarp) color of WR after milling is always red & 48 & 50 & 2 & 40 & 57 & 3 \\
\hline Grains of WR are all color red & 68 & 30 & 2 & 70 & 30 & - \\
\hline Flag leaves of WR are always drooping & 90 & 8 & 2 & 90 & 3 & 7 \\
\hline
\end{tabular}

${ }^{1}$ MA: most affected; SMA: second most affected.

The second most affected village also had the same six statements correctly thought of as false by majority of the respondents. The same two incorrect statements, namely, "flag leaves of weedy rice are always drooping” (90\%) and "grains of weedy rice are all color red" (70\%), were believed to be true by majority of the respondents. And the respondents from the second most affected village were also divided on whether "the grain (pericarp) color of weedy rice after milling is always red".

At least one third of the respondents from both villages had incorrect notions on three statements: weedy rice has only one kind of panicle, weedy rice can be harvested with cultivated rice, and weedy rice has only closed panicles. Note that two of these statements focused on the panicle characteristics of weedy rice.

During the FGD, the farmers were asked to expound on their incorrect belief that flag leaves of weedy rice are always drooping and that weedy rice grains are all red. It was observed that the incorrect belief on the flag leaf arose as majority of the farmers were not aware about the identification of the flag leaf. With regards to the color of the grain, the confusion was connected to the presence of the awns. As a great number of farmers believed that all weedy rice have awns, and those which have awns are mostly colored red, the farmers then concluded that weedy rice grains were all red. Based on field surveys in the province and on the brochure about weedy rice, flag leaves of weedy rice can be horizontal, erect, or drooping and grains after milling is color red.

\subsection{Knowledge of Management/Control of Weedy Rice}

The respondents were asked about their knowledge on the control of weedy rice. Nine statements were on the correct management practices for weedy rice and three statements showed incorrect management practices (Table 4).

For both villages, the same trend was observed. First, six statements were known by the majority from both villages as correct management practices for weedy rice. These statements were: 1) weedy rice problem will increase if seeds are exchanged with other rice farmers; 2) the best way to reduce weedy rice is by cutting the panicles at harvest; 3 ) repeated plowing during fallow period can reduce weedy rice; 4) thoroughly cleaning farm machinery (tractor or thresher/harvester) will help limitweedy rice infestation; 5) manual weeding is recommended/effective during serious infestation of weedy rice; and 6) field or irrigation canals should be cleared of weedy rice to limit infestation. The second trend was that more than one third of the respondents from both villages thought three statements to be incorrect. These statements were: 1) deep plowing will reduce weedy rice; 2) rotary weeder/cultivation can reduce weedy rice; and 3) early flooding has no effect on weedy rice infestation.

Flooding is considered an important component of cultural weed management in rice; however, the introduction of early flooding rather than a later flooding suppresses weeds more effectively. In research studies in Vietnam and the Philippines, early flooding was reported to suppress seedling emergence and growth of weedy rice and other weeds [11-13]. In Vietnam, a flooding depth of $5 \mathrm{~cm}$ or more was able to suppress germination and emergence of weedy rice [13]. In Malaysia, 5 to 10 -cm flooding depth was suggested to inhibit weedy rice emergence [3]. 
Though almost all farmers from both villages acknowledged that seed exchange worsens weedy rice problem, this fact had not hindered the practice in these areas. Based on the results of Table 1, 70\% of the farmers from the most affected village and $38 \%$ of the farmers from the second most affected village practiced seed exchange for the major variety they had planted in 2011. This practice may also be the reason why the most affected village was the worst infested by weedy rice. When asked during the FGD, the farmers from most affected village reasoned that they kept on planting farmer's seeds because certified seeds are expensive. On the other hand, the second most affected village may not be as badly infested by weedy rice because more than half of the respondents used certified seeds in 2011.

Cutting the panicles at harvest, as the best way of reducing weedy rice, was practiced by majority of the respondents (82\%) in the most affected village and only more than one-third (37\%) of the respondents in the second most affected village. Yet despite the fact that majority of the farmers from the most affected village used this correct management practice, the village persisted to be infested by weedy rice.

It should also be noted that the other management practices that the majority of the respondents from both villages knew as correct (repeated plowing during fallow period can reduce weedy rice, thoroughly cleaning farm machinery will help limit weedy rice infestation, field or irrigation canals should be cleared of weedy rice to limit infestation, and manual weeding is recommended/effecttive during serious infestation of weedy rice) were hardly or not at all practiced by these farmers. For these two sets of farmers, it does not mean that knowledge equates to practice.

From the knowledge statements on management of weedy rice, only three statements were presented to the farmers as incorrect (Table 5). These statements were: 1) available herbicides may reduce the weedy rice problem; 2) not preparing the land can reduce weedy rice; and 3) a high seeding rate will eliminate weedy rice. Similar trends were observed from the two villages. First, majority of farmers from both villages correctly knew that all

Table 4. Farmer-respondents knowledge of the correct or proper management of weedy rice (WR) in the Iloilo province of the Philippines $(\mathbf{N}=\mathbf{9 0})$.

\begin{tabular}{|c|c|c|c|c|c|c|}
\hline \multirow{2}{*}{ Management of weedy rice } & \multicolumn{3}{|c|}{$\%$ MA village ${ }^{1}(60)$} & \multicolumn{3}{|c|}{$\%$ SMA village ${ }^{1}(30)$} \\
\hline & True & False & Not Sure & True & False & Not Sure \\
\hline WR problem will increase if seeds are exchanged with other rice farmers & 96 & 2 & 2 & 97 & 3 & - \\
\hline The best way to reduce WR is by cutting the panicles at harvest & 92 & 7 & - & 73 & 23 & 3 \\
\hline $\begin{array}{l}\text { Thoroughly cleaning farm machinery (tractor or thresher/harvester) } \\
\text { will help limit WR infestation }\end{array}$ & 83 & 17 & - & 80 & 20 & - \\
\hline Repeated plowing during fallow period can reduce WR & 87 & 13 & - & 90 & 10 & - \\
\hline Manual weeding is recommended/effective during serious infestation of WR & 83 & 17 & - & 70 & 30 & - \\
\hline Field or irrigation canals should be cleared of WR to limit infestation & 68 & 32 & - & 77 & 23 & - \\
\hline Deep plowing will reduce WR & 53 & 43 & 3 & 63 & 37 & - \\
\hline Rotary weeder/cultivation can reduce WR & 38 & 45 & 18 & 37 & 43 & 20 \\
\hline Early flooding has no effect on WR infestation & 48 & 48 & 3 & 53 & 47 & - \\
\hline
\end{tabular}

${ }^{1}$ MA: most affected; SMA: second most affected.

Table 5. Farmer-respondents knowledge of incorrect management practices for weedy rice (WR) in the Iloilo province of the Philippines $(\mathrm{N}=\mathbf{9 0})$.

\begin{tabular}{ccccccc}
\hline \multirow{2}{*}{ Management of weedy rice } & \multicolumn{3}{c}{ \% MA village $^{1}(60)$} & \multicolumn{2}{c}{ \% SMA village $^{1}(30)$} \\
\cline { 2 - 7 } & True & False & Not Sure & True & False & Not Sure \\
\hline Available herbicides may reduce the WR problem & 10 & 86 & 4 & 6 & 91 & 3 \\
Not preparing the land can reduce WR. & 19 & 78 & 4 & 34 & 66 & - \\
A high seeding rate will completely eliminate WR & 16 & 79 & 5 & 37 & 63 & - \\
\hline
\end{tabular}

${ }^{1}$ MA: most affected; SMA: second most affected. 
three statements were incorrect. Additionally, the farmers' disagreement with the statement "available herbicides may reduce the weedy rice problem” clearly reflected in their practice as majority of them did not use herbicides in 2011. Follow-up questions showed why farmers did not use herbicides and the top three answers given by the farmers from both villages were: 1) herbicides were not effective for weedy rice; 2) there was no herbicides yet for weedy rice; and 3) herbicides were for weeds only. The third answer jibed with their belief that weedy rice is a type of rice and therefore using herbicides would not be appropriate. During the FGD, the farmers mentioned that if herbicides are available to manage weedy rice, they would most likely use it.

For the second most affected village, it should be noted that two statements were considered correct by more than one-third (34\% - 37\%) of the respondents. These statement were "not preparing the land can reduce weedy rice" (34\%) and "a high seeding rate will eliminate weedy rice” (37\%).

\subsection{Knowledge on the Problems Caused or Effects of Weedy Rice}

Farmer-respondents were asked six statements regarding the problems caused or effects of weedy rice (Table 6). Of these six statements, only one was incorrect (weedy rice does not affect the yield of cultivated rice). Both villages exhibited the same trend of responses for the six statements. Four out of the five correct problems caused by weedy rice or the effects of weedy rice were known to the majority of the farmers "as true". These were: 1) weedy rice decreases the yield of cultivated rice as it competes with sunlight, fertilizer, and other nutrients; 2) weedy rice reduces quality of rice/crop yield; 3) weedy rice decreases the number of tillers of cultivated rice; and 4) weedy rice can reduce the market value of the har- vested rice. The incorrect statement "weedy rice does not affect the yield of cultivated rice” was known as such to majority of the farmers in both villages. However, the statement "weedy rice mixture increases the milling cost" which is correct was thought of as erroneous by majority of the respondents from both villages.

Results showed that $41 \%$ from the second most affected village and 33\% from the most affected village thought that weedy rice cannot reduce the market value of the harvested rice. Research studies have found this to be otherwise $[2,3,6]$. The same is true for milling costs. Weedy rice increases the milling cost as the red layers or pericarp of weedy rice grains need to be removed by extra milling [14-16]. These studies also showed that this extra milling sometimes results in broken grain thus eventually reducing the commercial grade.

\section{Conclusions and Recommendation}

Farmers' knowledge of weedy rice did not differ much between two villages. Both had almost the same trends as to what they think were true and false. The only significant difference was that farmers from the second most affected villages knew that weedy rice is a weed in rice which may possibly contribute as to why they were not the most affected village (another factor may be the use of certified seeds by the farmers from second most affected villages).

A follow-up study is recommended on the effects of the awns on threshing activities and to measure the space taken by weedy rice with awns in farmers' rice sacks. This information will strengthen the statement that weedy rice is a growing menace in farmers' fields. It is suggested that a farmer or extension training be conducted in these villages, and we should focus more on correcting the wrong perceptions of farmers on weedy rice, especially on the critical attributes of this weed. Trainings should

Table 6. Farmer-respondents knowledge of the problems caused or effects of weedy rice (WR) in the Iloilo province of the Philippines ( $\mathbf{N}=\mathbf{9 0})$.

\begin{tabular}{|c|c|c|c|c|c|c|}
\hline \multirow{2}{*}{ Problems caused or effects of weedy rice } & \multicolumn{3}{|c|}{$\%$ MA village ${ }^{1}(60)$} & \multicolumn{3}{|c|}{$\%$ SMA village ${ }^{1}(30)$} \\
\hline & True & False & Not Sure & True & False & Not Sure \\
\hline $\begin{array}{l}\text { Weedy rice decreases the yield of cultivated rice as it competes } \\
\text { with sunlight, fertilizer, and other nutrients }\end{array}$ & 81 & 19 & - & 81 & 19 & - \\
\hline Weedy rice reduces quality of rice/crop yield. & 79 & 19 & 2 & 72 & 28 & - \\
\hline Weedy rice decreases the number of tillers of cultivated rice & 79 & 17 & 2 & 81 & 19 & - \\
\hline Weedy rice can reduce the market value of the harvested rice & 64 & 33 & 3 & 59 & 41 & - \\
\hline Weedy rice mixture increases the milling cost & 12 & 85 & 3 & 25 & 75 & - \\
\hline Weedy rice does not affect the yield of cultivated rice & 31 & 69 & - & 25 & 75 & - \\
\hline
\end{tabular}

${ }^{1}$ MA: most affected; SMA: second most affected. 
include farmers from both villages.

\section{REFERENCES}

[1] BAS (Bureau of Agricultural Statistics), "Country STAT Philippines,” 2012. www.countrystat.bas.gov.ph

[2] B. S. Chauhan, "Strategies to Manage Weedy Rice in Asia," Crop Protection, Vol. 48, 2013, pp. 51-56. http://dx.doi.org/10.1016/j.cropro.2013.02.015

[3] M. Azmi and S. M. R. Karim, "Weedy Rice-Biology, Ecology and Management," Malaysian Agricultural Research and Development Institute (MARDI), Kuala Lumpur, 2008, 56 Pages.

[4] A. M. Baltazar and J. D. Janiya, "Weedy Rice in the Philippines,” In: BB Baki, DV Chin and M Mortimer, Eds., Wild and Weedy Rice in Rice Ecosystems in Asia-A Review, Los Baños, Philippines, 2000, pp. 75-78.

[5] B. S. Chauhan, A. S. K. Abeysekara, M. S. Wickramarathe, S. D. Kalatunga and U. B. Wickrame, "Effect of Rice Establishment Methods on Weedy Rice (Oryza sativa L.) Infestation and Grain Yield of Cultivated Rice (Oryza sativa L.) in Sri Lanka,” Crop Protection, Vol. 55, 2014, pp. 42-49.

[6] J. C. Delouche, N. R. Burgos, D. R. Gealy, G. Z. de San Martin, R. Labrada, M. Larinde and C. Rosell, "Weedy Rices-Origin, Biology, Ecology and Control," FAO Plant Production and Protection Paper 188, FAO, Rome, 2007, 144 Pages.

[7] B. S. Chauhan and D. E. Johnson, "Weedy Rice (Oryza sativa L.) I. Grain Characteristics and Growth Response to Competition of Weedy Rice Variants from Five Asian Countries,” Weed Science, Vol. 58, No. 4, 2010, pp. 374380. http://dx.doi.org/10.1614/WS-D-09-00071.1

[8] H. S. Suh, "Weedy Rice,” National Institute of Crop Science, Rural Development Administration (RDA), Suwon, 2008, 240 Pages.
[9] N. R. Burgos, R. J. Norman, D. R. Gealy and H. Black, "Competitive N Uptake between Rice and Weedy Rice," Field Crops Research, Vol. 99, No. 2-3, 2006, pp. 96-105. http://dx.doi.org/10.1016/j.fcr.2006.03.009

[10] B. S. Chauhan and D. E. Johnson, "Competitive Interactions between Weedy Rice and Cultivated Rice as a Function of Added Nitrogen and the Level of Competition," Weed Biology and Management, Vol. 11, No. 4, 2011, pp. 202-209.

http://dx.doi.org/10.1111/j.1445-6664.2011.00421.x

[11] B. S. Chauhan, "Weed Ecology and Weed Management Strategies for Dry-Seeded Rice in Asia,” Weed Technology, Vol. 26, No. 1, 212, pp. 1-13. http://dx.doi.org/10.1614/WT-D-11-00105.1

[12] B. S. Chauhan, "Weedy rice, "(Oryza sativa) II. Response of Weedy Rice to Seed Burial and Flooding Depth," Weed Science, Vol. 60, No. 3, 2012, pp. 385-388. http://dx.doi.org/10.1614/WS-D-11-00213.1

[13] D. V. Chin, "Biology and Management of Barnyardgrass, Red Sprangletop and Weedy Rice,” Weed Biology and Management, Vol. 1, No. 1, 2001, pp. 37-41. http://dx.doi.org/10.1046/j.1445-6664.2001.00009.x

[14] M. Mortimer, S. Pandey and C. Piggin, "Weedy Rice: Approaches to Ecological Appraisal and Implications for Research Priorities,” In: B. B. Baki, D. V. Chin and M. Mortimer, Eds., Wild and Weedy Rice in Rice Ecosystems in Asia-A Review. Limited Proceedings No. 2, International Rice Research Institute, Los Baños, 2000, pp. 97105.

[15] A. Diarra, R. J. Smith Jr. and R. E. Talbert, "Interference of Red Rice (Oryza sativa) with Rice (O. sativa)," Weed Science, Vol. 33, No. 5, 1985, pp. 644-649.

[16] R. J. Smith Jr., "Control of Red Rice (Oryza sativa) in Water-Seeded Rice (O. sativa),” Weed Science, Vol. 29, No. 6, 1981, pp. 663-666. 